\title{
Characterization of a novel Vibrio pathogenicity island (VPI-2) encoding neuraminidase (nanH) among toxigenic Vibrio cholerae isolates
}

\author{
William S. Jermyn and E. Fidelma Boyd
}

Department of Microbiology, University College Cork, National University of Ireland, Cork, Ireland

\author{
Author for correspondence: E. Fidelma Boyd. Tel: +35321 4903624. Fax: +353214903101. \\ e-mail: f.boyd@ucc.ie
}

\begin{abstract}
Acquisition of virulence genes encoded on mobile genetic elements has played an important role in the emergence of pathogenic isolates of Vibrio cholerae, the causative agent of the diarrhoeal disease cholera. The genes encoding cholera toxin (ctxAB), the main cause of profuse secretory diarrhoea in cholera, are encoded on a filamentous bacteriophage $\mathrm{CTX} \phi$. The toxin coregulated pilus (TCP), an essential intestinal colonization factor, was originally designated as part of a pathogenicity island named the Vibrio pathogenicity island (VPI), but this island has more recently been proposed to be the genome of a filamentous phage, VPI $\phi$. In this study, it is shown that nanH, which encodes neuraminidase, maps within a novel pathogenicity island designated VPI-2. The $57.3 \mathrm{~kb}$ VPI-2 has all of the characteristic features of a pathogenicity island, including the presence of a bacteriophage-like integrase (int), insertion in a tRNA gene (serine) and the presence of direct repeats at the chromosomal integration sites. Additionally, the G+C content of VPI-2 (42 mol\%) is considerably lower than that of the entire genome (47 mol\%). VPI-2 encodes several gene clusters, such as a restriction modification system ( $h s d R$ and hsdM) and genes required for the utilization of amino sugars (nan-nag region) as well as neuraminidase. To determine the distribution of VPI-2 among $V$. cholerae, 78 natural isolates were examined using PCR and Southern hybridization analysis for the presence of this region. All toxigenic $V$. cholerae 01 serogroup isolates examined contained VPI-2, whereas non-toxigenic isolates lacked the island. Of $14 \mathrm{~V}$. cholerae 0139 serogroup isolates examined, only one strain, MO2, contained the entire $57.3 \mathrm{~kb}$ island, whereas 130139 isolates contained only a $20.0 \mathrm{~kb}$ region with most of the $5^{\prime}$ region of VPI-2 which included nanH deleted in these strains.
\end{abstract}

Keywords: virulence factors, bacteriophage, restriction modification

\section{INTRODUCTION}

Vibrio cholerae, a Gram-negative bacterium, is the aetiologic agent of the severe diarrhoeal disease cholera. Cholera has a predilection for pandemic spread and of the nearly 200 recognized serogroups of $V$. cholerae, only the O1 and O139 serogroups have been associated with epidemic cholera (Kaper et al., 1995). The O1

Abbreviations: $C T$, cholera toxin; $I S$, insertion sequence; $T C P$, toxin coregulated pilus; VPI, Vibrio pathogenicity island. serogroup is divided into two distinct biotypes, classical and $\mathrm{El}$ Tor, on the basis of a number of biochemical characteristics. To date, seven pandemics of cholera have been recorded. Little is known about the first four; however, the fifth and sixth pandemic were caused by the classical biotype and the present ongoing seventh pandemic, which began in 1961, is caused by the El Tor biotype (Barua, 1992). In 1992, a new epidemic serogroup, O139 Bengal, emerged and temporarily replaced the predominant O1 serogroup (Albert et al., 1993; Cholera Working Group, 1993; Ramamurthy et al., 1993). The emergence of this new O139 epidemic variant 


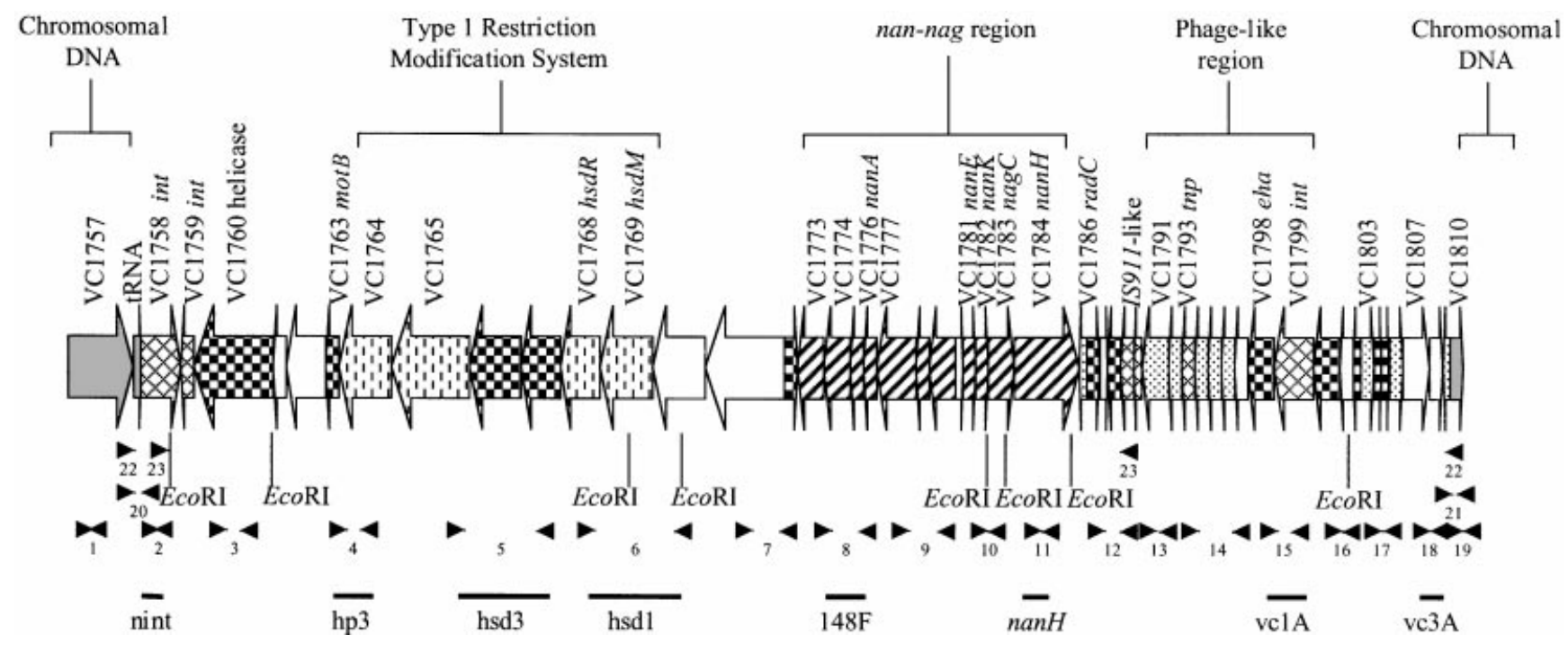

Fig. 1. Schematic representation and genetic organization of the $57 \cdot 3 \mathrm{~kb}$ VPI-2. The position and direction of transcription of the ORFs are indicated by the direction of the arrows. The dash-patterned arrows indicate the restriction modification system, diagonal-patterned arrows indicate the nan-nag region, spotted arrows indicate genes of bacteriophage origin, chequered arrows indicate genes encoding hypothetical proteins, hatched arrows indicate potential mobility genes, white arrows indicate genes that are unlike any other gene in the database and grey arrows indicate chromosomal genes flanking VPI-2. The black, bold horizontal lines indicate the location of the probes used in hybridization. The small black arrowheads indicate the position of the PCR primer pairs. Vertical black lines indicate the position of restriction enzyme sites.

is thought to have resulted from the horizontal transfer of the genes encoding the LPS O-antigen to an El Tor progenitor strain via a bacteriophage (Berche et al., 1994; Waldor \& Mekalanos, 1994; Bik et al., 1995, 1996; Comstock et al., 1995; Stroeher et al., 1997).

Interestingly, the main virulence factors of $V$. cholerae are also encoded on mobile genetic elements and are acquired via horizontal gene transfer. For example, the major symptoms of cholera result from the production of cholera toxin (CT) in the small intestine (Sears \& Kaper, 1996) and the $c t x A B$ genes encoding CT reside on a lysogenic filamentous phage, CTX $\phi$ (Waldor \& Mekalanos, 1996). The receptor for CTX $\phi$ on the $V$. cholerae cell is a type IV pilus, the toxin-coregulated pilus (TCP), that also functions as an essential intestinal colonization factor (Taylor et al., 1987). The genes encoding the biosynthesis of TCP were initially shown to reside on a pathogenicity island, designated the Vibrio pathogenicity island (VPI) (Kovach et al., 1996; Karaolis et al., 1998). As defined by Hacker et al. (1997) a pathogenicity island is a large unstable chromosomal region that encodes several virulence genes; is present in pathogenic isolates and absent from non-pathogenic isolates; has a $\mathrm{G}+\mathrm{C}$ content that differs from the rest of the genome; is associated with a tRNA gene; has IS and/or repeat sequences near the site of integration; and contains a bacteriophage-like integrase. The VPI fulfils all the criteria of a pathogenicity island and the identification of integrase and transposase genes at each end of the VPI suggests that they could be involved in the transfer and integration of this region (Karaolis et al., 1998). More recently, Karaolis and colleagues have suggested that the VPI is actually the genome of a novel filamentous bacteriophage VPI $\phi$; however, transfer of VPI $\phi$ between $V$. cholerae O1 and O139 serogroup isolates, the predominant cause of epidemic cholera, was not shown (Karaolis et al., 1999). Instead, a recent report by O'Shea \& Boyd (2002) demonstrated efficient transfer of the VPI region between $V$. cholerae O1 serogroup strains via CP-T1 generalized transduction.

In Vibrio cholerae neuraminidase, encoded by $n a n H$, is thought to increase the sensitivity of host cells to CT (Galen et al., 1992). It has been suggested that nanH from a number of bacterial pathogens has been acquired by horizontal gene transfer (Roggentin et al., 1993). In this study, we examined the nan $H$ gene and its flanking sequences among $V$. cholerae toxigenic (CTX $\phi$-positive) and non-toxigenic (CTX $\phi$-negative) isolates and found that the $n a n H$ gene is encoded within a $57 \cdot 3 \mathrm{~kb}$ region that showed all the characteristics of a pathogenicity island which we named VPI-2 (Fig. 1).

\section{METHODS}

Bacterial strains. A total of $78 \mathrm{~V}$. cholerae isolates from our laboratory collection were used in this study. The 78 strains examined were temporally (1947-1996) and geographically widespread (Africa, Asia, North and South America), of which 55 were toxigenic (CTX $\phi$-positive) and 23 were nontoxigenic (CTX $\phi$-negative), representing 14 serogroups, in- 
Table 1. $V$. cholerae toxigenic and non-toxigenic strains used in Southern hybridization analysis

All strains were from clinical sources.

\begin{tabular}{|lllll|}
\hline Strain & $\begin{array}{c}\text { Serogroup } \\
\text { (biotype) }\end{array}$ & $\boldsymbol{c t \boldsymbol { A } \boldsymbol { B }}$ & Location & Year \\
\hline O395 & O1 (classical) & + & India & 1964 \\
C5 & O1 (El Tor) & + & Indonesia & 1957 \\
569B & O1 (classical) & + & India & 1947 \\
SM115 & O1 (El Tor) & + & Bahrain & 1978 \\
N16961 & O1 (El Tor) & + & Bangladesh & 1975 \\
1528-79 & O1 & - & Louisiana & 1979 \\
MO2 & O139 & + & Madras & 1992 \\
MO10 & O139 & + & Madras & 1992 \\
MO45 & O139 & + & Madras & 1992 \\
AS207 & O139 & + & Calcutta & 1996 \\
AS209 & O139 & + & Calcutta & 1996 \\
AS210 & O139 & + & Calcutta & 1996 \\
V52 & O37 & - & Sudan & 1968 \\
SG3 & O32 & - & Calcutta & $1992 / 1993$ \\
SG6 & O45 & - & Calcutta & $1992 / 1993$ \\
SG7 & O56 & - & Calcutta & $1992 / 1993$ \\
SG10 & O69 & Calcutta & $1992 / 1993$ \\
\hline
\end{tabular}

cluding 36 O1 serogroup isolates, 14 O139 serogroup isolates and 28 isolates of the following serogroups: O8, O10, O11, O32, O35, O37, O42, O45, O56, O66, O69 and O141. V. cholerae isolates used for Southern hybridization analysis are listed in Table 1 . Bacterial strains were stored at $-70^{\circ} \mathrm{C}$ in Luria-Bertani (LB) broth containing 20\% glycerol. The antibiotic kanamycin was used at $40 \mu \mathrm{g} \mathrm{ml}^{-1}$.

Molecular analysis. Total genomic DNA from each bacterial isolate was extracted using the G-nome DNA isolation kit (Bio101). PCR analysis was carried out using 23 primer pairs (Table 2), the location of which can be seen in Fig. 1. PCR primers were designed based on the genome sequence of $V$. cholerae O1 serogroup strain N16961 (Heidelberg et al., 2000). PCR was performed in volumes of $20 \mu \mathrm{l}$ containing $10 \mathrm{ng}$ genomic DNA, $10 \mathrm{pmol}$ primer and $1 \mathrm{U}$ Taq DNA polymerase. The amplification conditions were pre-incubation at $96{ }^{\circ} \mathrm{C}$ for $1 \mathrm{~min}$, followed by 30 cycles of $94{ }^{\circ} \mathrm{C}$ for $30 \mathrm{~s}$, $48-55^{\circ} \mathrm{C}$ (depending on the primer pair) for $30 \mathrm{~s}$ and $72{ }^{\circ} \mathrm{C}$ for a time chosen based on the size of the expected fragment ( 1 min per kb). All PCRs were carried out in a PTC-200 Peltier Thermal Cycler (MJ Research).

Southern hybridization was carried out with eight DNA probes generated by PCR from the reference strain N16961 as template. PCR products were purified using the ConcertPCR purification kit (Gibco-BRL). For Southern hybridization analysis, DNA from each strain was digested with the restriction enzyme EcoRI (Roche Molecular Biochemicals) and the fragments were separated by electrophoresis in $0.6 \%$ TBE agarose. The gel was depurinated with $0 \cdot 25 \mathrm{M} \mathrm{HCl}$ for $10 \mathrm{~min}$, denatured with a solution of $5 \mathrm{M} \mathrm{NaCl}$ and $10 \mathrm{M}$ $\mathrm{NaOH}$ for $40 \mathrm{~min}$ and neutralized with $1 \mathrm{M}$ Tris and $20 \times$ SSC for $40 \mathrm{~min}$. The fragments were transferred to nitrocellulose membrane by a Posiblotter (Stratagene). DNA was fixed to the membrane by UV cross-linking. Approximately
200 ng probe DNA was conjugated to horseradish peroxidase using the ECL direct nucleic acid labelling system (Amersham Pharmacia Biotech) and after hybridization overnight was detected by the ECL chemiluminescent substrate. Hybridization membranes were washed according to manufacturer's instructions.

Sequence analysis. A region spanning $57 \cdot 3 \mathrm{~kb}$ from position 1896092 to 1953461 of the $V$. cholerae genome from strain N16961 (Heidelberg et al., 2000) was analysed for sequence similarities using the BLAST algorithm (Altschul et al., 1997). DNA sequence analysis was carried out on both DNA strands of the $\mathrm{fk} 3 / \mathrm{fk} 4$ purified PCR product by MWG-Biotech and the resulting sequence was examined using BLAST (Altschul et al., 1997).

\section{RESULTS}

\section{Association of nanH with toxigenic V. cholerae}

To determine whether there is a correlation between the presence of $n a n H$ and the presence of CTX $\phi$ among $V$. cholerae isolates, the distribution of the nanH gene among 78 toxigenic (CXT $\phi$-positive) and non-toxigenic (CTX $\phi$-negative) isolates of $V$. cholerae was examined. Of the $30 \mathrm{O} 1$ and 11 non-O1/O139 serogroup toxigenic isolates examined by PCR analysis with the primer pair nanH1 and nanH2, all gave a positive $1.9 \mathrm{~kb}$ PCR band. In contrast, 20 of the 23 non-toxigenic $V$. cholerae isolates examined failed to give a PCR amplification product. The three non-toxigenic strains that gave a $1.9 \mathrm{~kb}$ positive PCR band, 468-83, 2740-80, E714, were all $\mathrm{O} 1$ serogroup strains. Of the 14 toxigenic O139 serogroup isolates examined, only one strain, MO2, 
Table 2. Oligonucleotide primer sequences used for PCR

All primers were designed in this study.

\begin{tabular}{|c|c|c|c|}
\hline $\begin{array}{l}\text { Primer } \\
\text { no. }\end{array}$ & Name & Sequence $\left(5^{\prime}-\mathbf{3}^{\prime}\right)$ & $\begin{array}{l}\text { Product size } \\
(\mathbf{k b})\end{array}$ \\
\hline \multirow[t]{2}{*}{1} & acrB1 & GGCTACATCAGCTACCTC & $2 \cdot 9$ \\
\hline & acrB2 & GCGGGATCACGACTAAG & \\
\hline \multirow[t]{2}{*}{2} & nint3 & ATCTGATGGCGGCAATC & $1 \cdot 0$ \\
\hline & $\operatorname{nint} 4$ & GCGGCTTCAATGACATC & \\
\hline \multirow[t]{2}{*}{3} & helF & GATCAGCACCATTGTTCG & $2 \cdot 3$ \\
\hline & helR & CGTTCCTGGAAAACCCTAC & \\
\hline \multirow[t]{2}{*}{4} & hp3 & CGGTCTTTCTTCTGAATTGC & $0 \cdot 9$ \\
\hline & hp4 & TCGGCGAATGAGTTACGAG & \\
\hline \multirow[t]{2}{*}{5} & hsd3 & GCTTAGTCGTCATATAGACTTC & $3 \cdot 9$ \\
\hline & hsd4 & TCCCTATCGCTGGAATG & \\
\hline \multirow[t]{2}{*}{6} & hsd1 & TCCATGCCCACATTATG & $4 \cdot 5$ \\
\hline & hsd2 & CGCTGCATTAACCTTGC & \\
\hline \multirow[t]{2}{*}{7} & ukf & GTTAGCACTGGCTCTACC & $3 \cdot 4$ \\
\hline & repr & CCGCAAGATAAGTATTGATGTC & \\
\hline \multirow[t]{2}{*}{8} & $148 \mathrm{~F}$ & CATTAGAGTTTTCTCCCC & $4 \cdot 2$ \\
\hline & 146B & AACAGGTTTGATTGCTGC & \\
\hline \multirow[t]{2}{*}{9} & $147 \mathrm{~F}$ & CCCATAACCATCAGAGC & $2 \cdot 3$ \\
\hline & $146 \mathrm{~A}$ & CGCAATACTTACTTTGAGTG & \\
\hline \multirow[t]{2}{*}{10} & nagC1 & CATACAGCGTTACCAGATAG & $2 \cdot 1$ \\
\hline & nagA2 & ACGTTGCAGTTATGTTCG & \\
\hline \multirow[t]{2}{*}{11} & nanH1 & GACAGTCCAGCCAAACAG & $1 \cdot 9$ \\
\hline & nanH2 & CGTTAGCGTTGTTAGCCTC & \\
\hline \multirow[t]{2}{*}{12} & $\operatorname{radC1}$ & CACGGAATACTTACGCTG & $1 \cdot 8$ \\
\hline & isB2 & CCAAGAACCAAAGCATCGTTAC & \\
\hline \multirow[t]{2}{*}{13} & isA1 & TCGGCTCAGCTTTACAC & $1 \cdot 4$ \\
\hline & is $\mathrm{A} 2$ & TTTCGGTAATCGACTGC & \\
\hline \multirow[t]{2}{*}{14} & is 93 & ATGGGGATCTCACTGCTG & $3 \cdot 2$ \\
\hline & mu4 & GATGTGCCGAAATGATCG & \\
\hline \multirow[t]{2}{*}{15} & $\mathrm{vc} 1 \mathrm{~A}$ & CCTCTTTGGTTGGGTTC & $2 \cdot 2$ \\
\hline & $\mathrm{vc} 2 \mathrm{~A}$ & GACTACCAGAGACTTACGC & \\
\hline \multirow[t]{2}{*}{16} & $\mathrm{vc} 1 \mathrm{~B}$ & GGTCAGGAAATCCAAATCTAGG & $0 \cdot 9$ \\
\hline & $\mathrm{vc} 2 \mathrm{~B}$ & TTACGGCTCGCTTTAGAG & \\
\hline \multirow[t]{2}{*}{17} & $\mathrm{vc} 3 \mathrm{~A}$ & CCTATTTTGCAGTTGGTGC & $2 \cdot 5$ \\
\hline & $\mathrm{vc} 4 \mathrm{~A}$ & CGCTAATGTTTTTCCAGAGTGG & \\
\hline \multirow[t]{2}{*}{18} & $\mathrm{vc} 3 \mathrm{~B}$ & CGTACCATTTCCAATGATGCAG & $2 \cdot 3$ \\
\hline & $\mathrm{vc} 4 \mathrm{~B}$ & GAAGTGCTAACTATGACTGG & \\
\hline \multirow[t]{2}{*}{19} & $\mathrm{vc} 5 \mathrm{~B}$ & GCATGATCGCTCAATCC & $1 \cdot 2$ \\
\hline & vc6B & GCCTGTTTTTCGAGGTTG & \\
\hline \multirow[t]{2}{*}{20} & $\operatorname{lr} 1$ & GGATTCGGTCGATACTGTC & $1 \cdot 6$ \\
\hline & $\operatorname{lr} 2$ & TCGTAGCCTTCCATTGC & \\
\hline \multirow[t]{2}{*}{21} & $1808 \mathrm{~F}$ & ATATGAGAGCAAGGGAAGTG & $2 \cdot 8$ \\
\hline & vc6A & CGCTCTGTTGTAACGAGATG & \\
\hline \multirow[t]{2}{*}{22} & $\mathrm{fk} 1$ & CTGGCTATGAGCTGATTTG & $1 \cdot 0$ \\
\hline & $\mathrm{fk} 2$ & AGGGATTGGCTTTGAGG & \\
\hline \multirow[t]{2}{*}{23} & $\mathrm{fk} 3$ & TCTAGCCGTAATCCAAAGG & $3 \cdot 8$ \\
\hline & $\mathrm{fk} 4$ & AGATCACCCGCTACATTATC & \\
\hline
\end{tabular}

which was clinically isolated in Madras in 1992, gave a positive PCR band with the nanH primer pair (Table 3).

The PCR results were verified by Southern hybridization analysis using a $1.9 \mathrm{~kb}$ probe for the nanH gene generated by PCR from strain N16961 genomic DNA with the primer pair nanH1/nanH2. An identical hybridization fragment was obtained for seven toxigenic $V$. cholerae strains examined and as expected, no hybridization fragment was obtained for the five non- 
Table 3. PCR analysis of VPI-2 among 78 toxigenic and non-toxigenic $V$. cholerae isolates

\begin{tabular}{|c|c|c|c|c|c|c|c|c|c|c|c|c|c|c|c|c|c|c|}
\hline & $\begin{array}{r}\text { acrB1/ } \\
\text { acrB2 }\end{array}$ & $\begin{array}{r}\operatorname{nint} 3 / \\
\operatorname{nin} 4\end{array}$ & $\begin{array}{l}\text { helF/ } \\
\text { helR }\end{array}$ & $\begin{array}{l}\text { hp3/ } \\
\text { hp4 }\end{array}$ & $\begin{array}{r}\text { hsd3/ } \\
\text { hsd4 }\end{array}$ & $\begin{array}{l}\text { hsd1/ } \\
\text { hsd2 }\end{array}$ & $\begin{array}{l}\text { ukf/ } \\
\text { repr }\end{array}$ & $\begin{array}{l}148 \mathrm{~F} / \\
146 \mathrm{~B}\end{array}$ & $\begin{array}{l}147 \mathrm{~F} / \\
146 \mathrm{~A}\end{array}$ & $\begin{array}{c}\text { nagC1/ } \\
\text { nagA2 }\end{array}$ & $\begin{array}{r}\text { nanH1/ } \\
\text { nanH2 }\end{array}$ & $\begin{array}{l}\operatorname{radC1} / \\
\text { isB2 }\end{array}$ & $\begin{array}{l}\text { isA1/ } \\
\text { isA2 }\end{array}$ & $\begin{array}{l}\text { is93/ } \\
\text { mu4 }\end{array}$ & $\begin{array}{l}\mathrm{vc1A} / \\
\mathrm{vc} 2 \mathrm{~A}\end{array}$ & $\begin{array}{l}\mathrm{vc1B} / \\
\mathrm{vc} 2 \mathrm{~B}\end{array}$ & $\begin{array}{l}\mathrm{vc} 3 \mathrm{~A} / \\
\mathrm{vc} 4 \mathrm{~A}\end{array}$ & $\begin{array}{l}\mathrm{vc5B} \\
\mathrm{vc6B}\end{array}$ \\
\hline O1 toxigenic & + & + & + & + & + & + & + & + & + & + & + & + & + & + & + & + & + & + \\
\hline $\begin{array}{l}\text { Non-O1/non-O139 } \\
\text { toxigenic }\end{array}$ & + & + & + & + & + & + & + & + & + & + & + & + & + & + & + & + & + & + \\
\hline O139* & + & + & - & - & - & - & - & - & - & - & - & - & + & + & + & + & + & + \\
\hline Non-toxigenic $\dagger$ & + & - & - & - & - & - & - & - & - & - & - & - & - & - & - & - & - & + \\
\hline
\end{tabular}

* One O139 strain, MO2, isolated from Madras, India, in 1992 contained a full VPI-2, whereas all other O139 strains examined contained a truncated $20 \cdot 0 \mathrm{~kb}$ VPI-2 region. †Includes both O1 and non-O1/non-O139 serogroup isolates. All non-toxigenic isolates examined lacked VPI-2 except for three strains: $468-83$, $2740-80$ and E714. 


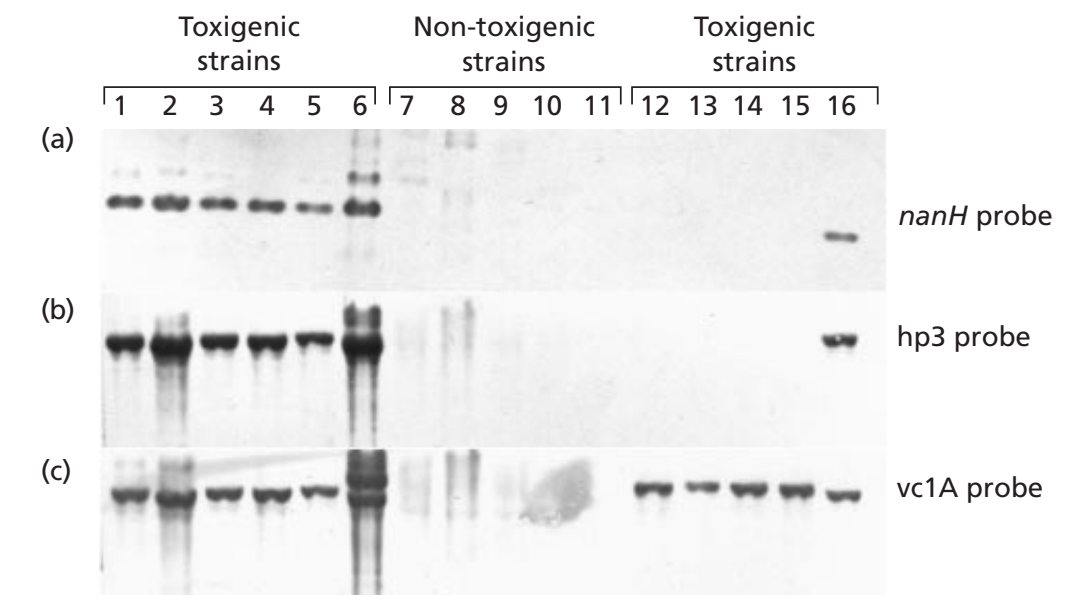

Fig. 2. Southern hybridization analysis of EcoRI-digested chromosomal DNA to verify the presence of VPI-2 in toxigenic $V$. cholerae isolates and absence of VPI-2 in non-toxigenic $V$. cholerae isolates. Lanes: 1 , 569B; 2, SM115; 3, C5; 4, N16961; 5, MO2; $6, \mathrm{~V} 52 ; 7,1528-79 ; 8$, SG3; 9, SG6; 10, SG7; 11, SG10; 12, AS207; 13, AS209; 14, MO10; 15, MO45; 16, O395. Probes used are indicated on the right. (a) Hybridization of DNA with the single-stranded nanH probe produced the expected $3.1 \mathrm{~kb}$ fragment and was obtained in all VPI-2-positive strains (lanes 1-6 and 16). No fragment was obtained in the 0139 strains lacking the $5^{\prime}$ region of the island (lanes 12-15). (b) Hybridization of DNA with the singlestranded hp3 probe specific for a $5^{\prime}$ region of VPI-2 produced the expected $14.3 \mathrm{~kb}$ fragment in all VPI-2-positive strains (lanes 1-6 and 16). No fragment was obtained in the 0139 strains lacking the $5^{\prime}$ region of the island (lanes 12-15). (c) Hybridization of DNA with the single-stranded vc1A probe specific for a 3 ' region of VPI-2 produced the expected $11.9 \mathrm{~kb}$ fragment in all VPI-2positive strains (lanes 1-6 and 16) and the 0139 strains containing the $3^{\prime}$ region of the island (lanes 12-15). For each probe used no fragment was obtained in VPI-2-negative strains (lanes 7-11).

toxigenic strains examined (Fig. 2a and Table 1). Thus, a $3.1 \mathrm{~kb}$ hybridization fragment was obtained for O1 serogroup strains O395 (classical biotype), 569B (classical biotype), C5 (El Tor biotype), SM115 (El Tor biotype) and N16961 (El Tor biotype), one O139 serogroup strain MO2 and a non O1/O139 serogroup strain V52, which was associated with the cholera outbreak in Sudan in 1968. Therefore, it appears that the nanH gene is present in toxigenic V. cholerae and is absent from non-toxigenic isolates.

\section{Association of nanH with a pathogenicity island}

The association of nanH with toxigenic $V$. cholerae isolates prompted us to examine the region flanking nanH in the genome sequence of strain N16961 (Heidelberg et al., 2000). A putative bacteriophage-like integrase gene (int), which is located adjacent to a serine tRNA gene, was identified $35.9 \mathrm{~kb}$ upstream of nanH. To determine whether there was an association between the presence of int and nanH, we carried out PCR analysis with the PCR primers for the int gene, nint 3 and nint4 (Table 2), to examine the distribution of int among nan $H$-positive and nanH-negative $V$. cholerae isolates. Of the 45 nan $H$-positive strains examined, all gave an expected $1.0 \mathrm{~kb}$ PCR band, indicating the presence of int in these strains. In contrast, PCR analysis of the 20 nanH-negative $V$. cholerae non-toxigenic isolates failed to amplify a PCR band with nint 3 and nint 4 primers, indicating the absence of int in these strains. Unexpectedly, PCR analysis of the 13 nanH-negative O139 serogroup strains gave a $1.0 \mathrm{~kb}$ PCR band, indicating the presence of int in these strains (Table 3). Southern hybridization analysis of chromosomal DNA from nan $H$-positive and nan $H$-negative isolates with an int probe verified the absence of int in nan $H$-negative $V$. cholerae isolates.

We used PCR analysis to investigate whether the DNA sequence between the int and the $n a n H$ genes is present among V. cholerae isolates. Eight primer pairs (3-10) were designed to encompass the $35.9 \mathrm{~kb}$ region of interest (Fig. 1 and Table 2). Positive PCR bands were obtained with all eight primer pairs for the $45 \mathrm{nanH}$ - and int-positive $V$. cholerae strains. No PCR products were obtained for $n a n H$ - and int-negative V. cholerae strains. Similarly, no PCR products were obtained for the 13 nan $H$-negative O139 serogroup strains that tested positive for int (Table 3). The absence of $35.9 \mathrm{~kb}$ between int and nan $H$ among non-toxigenic V. cholerae was verified by Southern hybridization using six DNA probes (nint, hp3, hsd3, hsd1, 148F and nanH) derived from PCR fragments generated using primer pairs from Table 2, which span the regions of interest (Fig. 1). No hybridization fragments were obtained with the DNA probes (hp3, hsd1, hsd3 and 148F) for the nine nanH-negative strains tested (1528-79, SG3, SG6, SG7, SG10, AS207, AS209, MO10 and MO45) and, as expected, positive hybridization bands were obtained for all $n a n H$-positive $V$. cholerae strains (Fig. 2b and data not shown).

PCR analysis was also used to investigate whether the region immediately upstream of serine tRNA and int is present among $V$. cholerae isolates. The primer pair acrB1 and acrB2 was designed to PCR-amplify the gene 


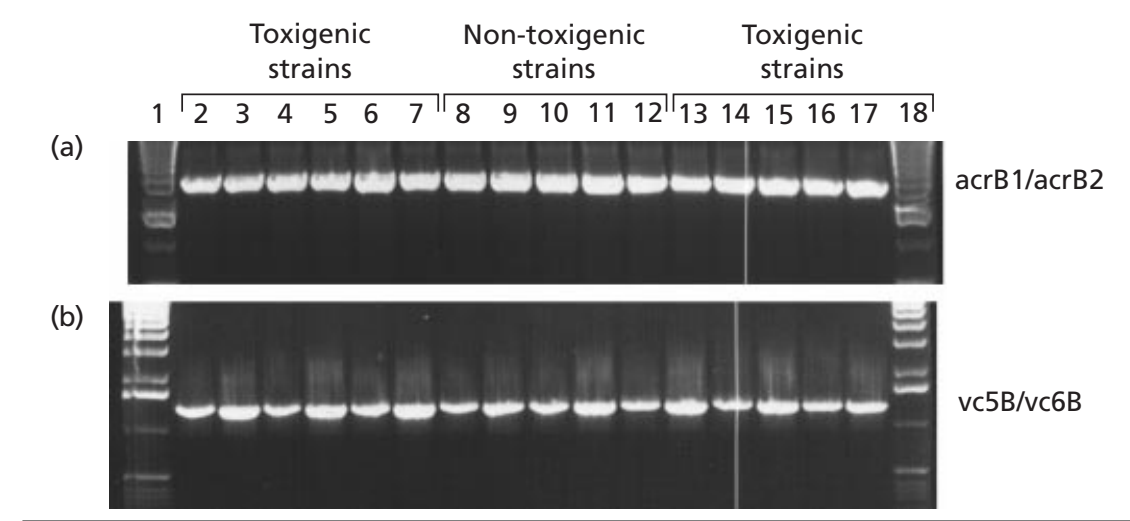

Fig. 3. $P C R$ analysis of the chromosomal junction of VPI-2. Lanes: $1,18,1 \mathrm{~kb}$ molecular mass marker; $2,569 \mathrm{~B} ; 3, \mathrm{SM} 115$; 4 , C5; 5, N16961; 6, MO2; 7, V52; 8, 152879; 9, SG3; 10, SG6; 11, SG7; 12, SG10; 13, AS207; 14, AS209; 15, MO10; 16, MO45; 17, O395. (a) An identical $2.9 \mathrm{~kb}$ product was obtained in all strains, both VPI-2-positive and -negative (lanes 2-17), using the primer pair acrB1 and acrB2. This PCR identified the chromosomal region flanking VPI-2 at the $5^{\prime}$ end. (b) An identical $1.2 \mathrm{~kb}$ product was obtained in all strains, both VPI-2-positive and -negative (lanes 2-17), using the primer pair vc5B and vc6B. This PCR identified the chromosomal region flanking VPI-2 at the 3' end.
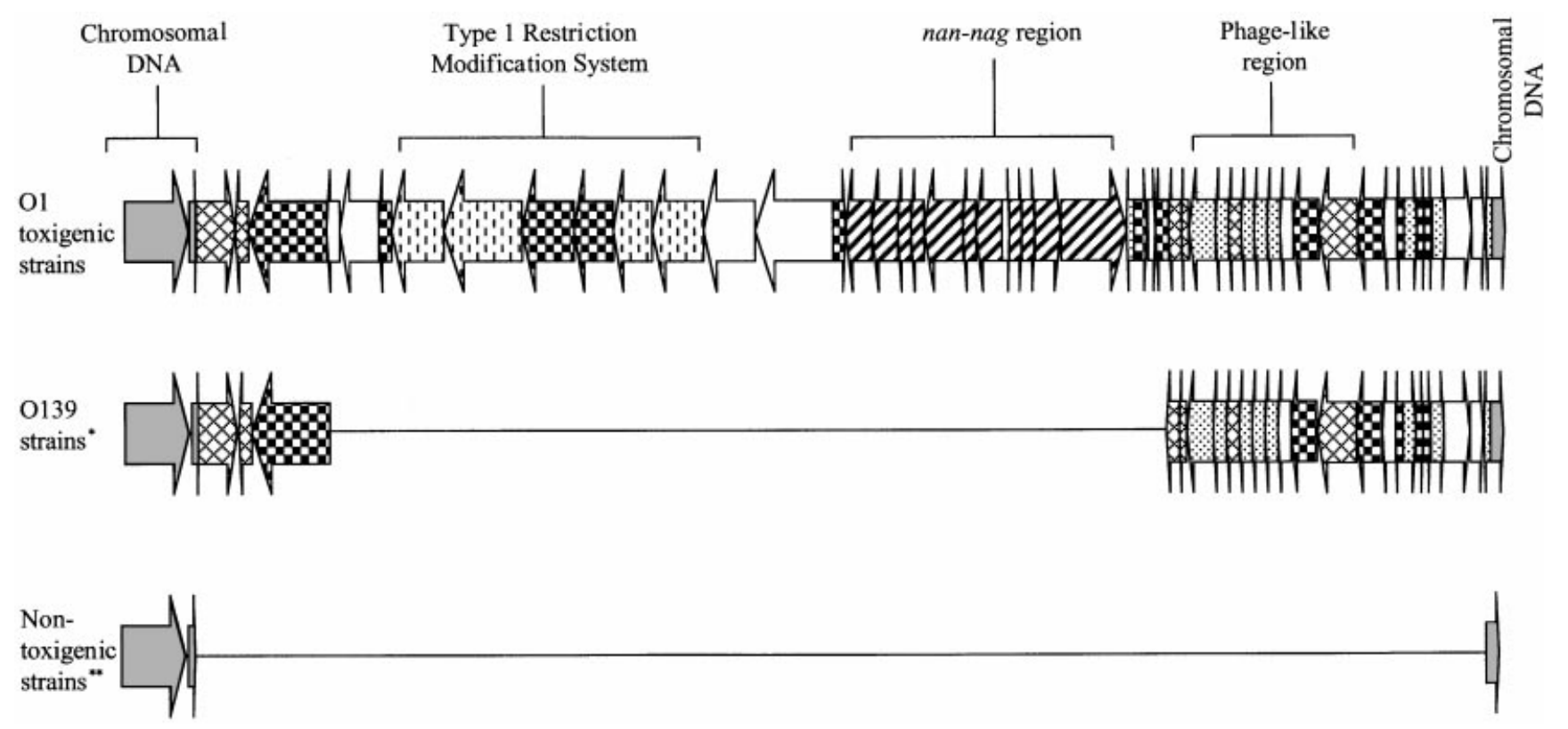

Fig. 4. The structure of VPI-2 among $V$. cholerae strains. An arrow denotes the presence of each individual VPI-2 ORF, whereas a thin black line denotes absence. The grey arrow at either end of VPI-2 denotes chromosomal DNA that is present in all strains. Three specific regions that are discussed in the text are labelled. *One 0139 strain, $\mathrm{MO2}$, isolated from Madras, India, in 1992 contained a full VPI-2, whereas all other 0139 strains examined contained only a truncated VPI-2 containing 24 ORFs shown. **Includes both 01 and non-O1/non-0139 serogroup isolates. All non-toxigenic isolates examined lacked VPI-2 except for three strains: 468-83, 2740-80 and E714. No significant additional DNA has replaced the ORFs that are absent in both the 0139 strains and non-toxigenic strains.

VC1757 immediately $5^{\prime}$ of the serine tRNA gene (Table 3). An identical $2 \cdot 9 \mathrm{~kb}$ PCR band was obtained for all $V$. cholerae isolates examined (Fig. 3a). Therefore, it appears that the serine tRNA gene marks the point of insertion of the $39.5 \mathrm{~kb}$ region (int-nanH) that is only associated with toxigenic V. cholerae isolates.

We then tested whether the flanking DNA 3' of nanH was present in all $V$. cholerae isolates. A PCR primer walking method was used; eight primer pairs (12-19) were designed downstream of nanH from the genome sequence of the strain N16961 (Heidelberg et al., 2000) and used to PCR-amplify the corresponding regions in V. cholerae isolates (Fig. 1 and Table 2). This analysis revealed the presence of an additional $17 \cdot 8 \mathrm{~kb}$ region that is unique to nanH-positive $V$. cholerae isolates. Thus, the 45 nanH-positive $V$. cholerae strains gave positive PCR bands with seven sets of primer pairs (12-18), whereas no PCR products were obtained for the $n a n H$-negative isolates with the exception of the 13 nanH-negative O139 serogroup strains; these strains gave positive PCR bands with six of the primer pairs (13-18), indicating the presence of this region in these isolates (Table 3). Two DNA probes (vc1A and vc3A) 
Table 4. ORFs within the $V$. cholerae VPI-2 pathogenicity island

\begin{tabular}{|c|c|c|c|c|}
\hline ORF & $\begin{array}{l}\text { Length } \\
\text { (aa) }\end{array}$ & Homologous protein (organism)* & $\begin{array}{l}\text { Amino acid } \\
\text { identity }(\%)\end{array}$ & $E$ value \\
\hline VC1758 & 411 & Integrase (V. cholerae) & 51 & e-113 \\
\hline VC1759 & 159 & Integrase $(V$. cholerae $)$ & 89 & e-123 \\
\hline VC1760 & 940 & Helicase (Bacillus subtilis) & 29 & $1 e-41$ \\
\hline VC1761 & 202 & No significant match & - & - \\
\hline VC1762 & 483 & No significant match & - & - \\
\hline VC1763 & 244 & Chemotaxis protein MotB (Aquifex aeolicus) & 29 & $0 \cdot 013$ \\
\hline VC1764 & 706 & Methyl-accepting subunit (Deinococcus radiodurans) & 21 & $1 \mathrm{e}-04$ \\
\hline VC1765 & 1022 & Restriction enzyme helicase subunit (Xylella fastidiosa) & 38 & e-178 \\
\hline VC1766 & 663 & Hypothetical protein $(P$. multocida $)$ & 26 & $8 e-36$ \\
\hline VC1767 & 470 & Hypothetical protein NMA2230 (Neisseria meningitidis) & 41 & $2 \mathrm{e}-04$ \\
\hline VC1768 & 462 & Type I restriction enzyme (Xylella fastidiosa) & 51 & $1 e-47$ \\
\hline VC1769 & 793 & Type I restriction DNA methylase (Xylella fastidiosa) & 42 & $2 \mathrm{e}-78$ \\
\hline VC1770 & 687 & No significant match & - & - \\
\hline VC1771 & 1220 & No significant match & - & - \\
\hline VC1772 & 286 & Hypothetical protein NMA1157 (Neisseria meningitidis) & 29 & $7 e-16$ \\
\hline VC1773 & 356 & Hypothetical protein HI0148 (Haemophilus influenzae) & 29 & $2 \mathrm{e}-36$ \\
\hline VC1774 & 384 & Hypothetical protein HI0148 (Haemophilus influenzae) & 36 & $4 \mathrm{e}-58$ \\
\hline VC1775 & 278 & Hypothetical protein HI0143 (Haemophilus influenzae) & 28 & $4 \mathrm{e}-22$ \\
\hline VC1776 & 298 & N-Acetylneuraminidase lyase HI0142 (Haemophilus influenzae) & 27 & $9 e-17$ \\
\hline VC1777 & 427 & C4-Dicarboxylase transporter HI0147 (Haemophilus influenzae) & 48 & $9 e-87$ \\
\hline VC1778 & 173 & C4-Dicarboxylase transporter HI0147 (Haemophilus influenzae) & 33 & $1 \mathrm{e}-13$ \\
\hline VC1779 & 321 & C4-Dicarboxylase binding protein HI0146 (Haemophilus influenzae) & 51 & $7 e-77$ \\
\hline VC1780 & 97 & No significant match & - & - \\
\hline VC1781 & 240 & $\begin{array}{l}\text { N-Acetylmannosamine-6-phosphate 2-epimerase HI0145 (Haemophilus } \\
\text { influenzae) }\end{array}$ & 52 & $1 \mathrm{e}-55$ \\
\hline VC1782 & 287 & N-Acetylmannosamine amide kinase HI0144 (Haemophilus influenzae) & 37 & $7 e-40$ \\
\hline VC1783 & 378 & $\begin{array}{l}\text { N-Acetylamide glucosamide-6-phosphate deacetylase HI0140 } \\
\text { (Haemophilus influenzae) }\end{array}$ & 35 & $7 e-42$ \\
\hline VC1784 & 807 & Neuraminidase (Bacteroides fragilis) & 25 & $5 \mathrm{e}-06$ \\
\hline VC1785 & 68 & DNA binding protein (P4 bacteriophage) & 54 & $4 \mathrm{e}-08$ \\
\hline VC1786 & 158 & RadC DNA repair (Xylella fastidiosa) & 53 & $3 e-32$ \\
\hline VC1787 & 45 & No significant match & - & - \\
\hline VC1788 & 231 & Hypothetical protein chromosome II (V. cholerae) & 100 & 0 \\
\hline VC1789 & 290 & IS911 & 66 & $1 \mathrm{e}-106$ \\
\hline VC1790 & 114 & IS911 & 72 & $5 e-31$ \\
\hline VC1791 & 346 & Mu-like gp42 (Mu prophage) & 35 & $4 \mathrm{e}-48$ \\
\hline VC1792 & 119 & Mu-like gp41 (Mu prophage) & 33 & $1 \mathrm{e}-05$ \\
\hline VC1793 & 125 & Transposase (Caenorhabditis elegans) & 32 & $3 \cdot 4$ \\
\hline VC1794 & 192 & gp12 protein (PSA bacteriophage) & 25 & $4 \cdot 0$ \\
\hline VC1795 & 106 & MOR protein (Mu phage) & 28 & $0 \cdot 26$ \\
\hline VC1796 & 124 & MOR protein (Mu phage) & 29 & $3 e-05$ \\
\hline VC1797 & 153 & No significant match & - & - \\
\hline VC1798 & 383 & Eha protein (Salmonella typhi) & 43 & $6 e-37$ \\
\hline VC1799 & 585 & Integrase (Salmonella typhimurium LT2) & 21 & $0 \cdot 002$ \\
\hline VC1800 & 323 & Plasmid replication protein C (Clostridium butyricum) & 27 & $4 \cdot 0$ \\
\hline VC1801 & 120 & No significant match & - & - \\
\hline VC1802 & 78 & Transcriptional regulator (Salmonella typhi) & 37 & $3 \cdot 0$ \\
\hline VC1803 & 153 & Repressor protein (CP-933O prophage) & 33 & $0 \cdot 56$ \\
\hline VC1804 & 104 & Hypothetical protein VC0509 (V. cholerae) & 55 & $1 \mathrm{e}-28$ \\
\hline VC1805 & 148 & Hypothetical protein VC0508 (V. cholerae) & 55 & $8 \mathrm{e}-47$ \\
\hline VC1806 & 328 & Replicase (Fr bacteriophage) & 38 & $0 \cdot 35$ \\
\hline VC1807 & 214 & No significant match & - & - \\
\hline VC1808 & 281 & No significant match & - & - \\
\hline VC1809 & 76 & Vis protein ( $\mathrm{P} 4$ bacteriophage) & 50 & $3 e-11$ \\
\hline
\end{tabular}

* Homology based on BLASTP database analysis. 


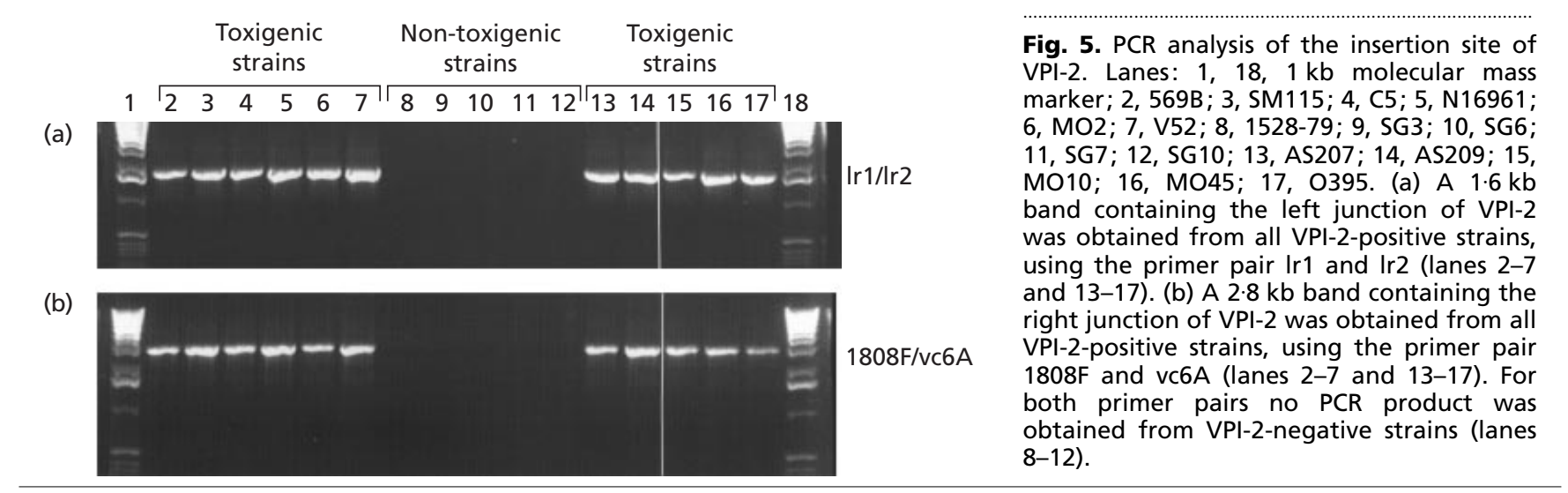

Fig. 5. $P C R$ analysis of the insertion site of VPl-2. Lanes: 1, 18, $1 \mathrm{~kb}$ molecular mass 6 , MO2; 7, V52; 8, 1528-79; 9, SG3; 10, SG6; MO10; 16, MO45; 17, O395. (a) A $1.6 \mathrm{~kb}$ was obtained from all VPI-2-positive strains, using the primer pair Ir1 and Ir2 (lanes 2-7 right junction of VPI-2 was obtained from all $1808 \mathrm{~F}$ and vc6A (lanes 2-7 and 13-17). For 8-12).
Fig. 6. Schematic diagram and nucleotide sequence of VPI-2 direct repeats (DR). In VPI2-negative strains, a single copy of the $7 \mathrm{bp}$ repeat is located at the $3^{\prime}$ end of the serine tRNA gene. Integration of the island produces a second copy of the repeat at the $3^{\prime}$ end of the pathogenicity island. The DNA sequence at the $3^{\prime}$ end of the serine tRNA gene and the $3^{\prime}$ end of the pathogenicity island (PAI) is shown, with the DR sequence given in bold type.
tRNA DR ACGCCTGGAAAGTGTGTATACGGCAACGTATCGAGAGTTCG PAI DR ACCACTTGGAGTTGTATATACGGTTAGAGCAAGAGGTTGTA
$V$. cholerae non-

$V$. cholerae $\mathrm{O} 1$ toxigenic isolates toxigenic isolates

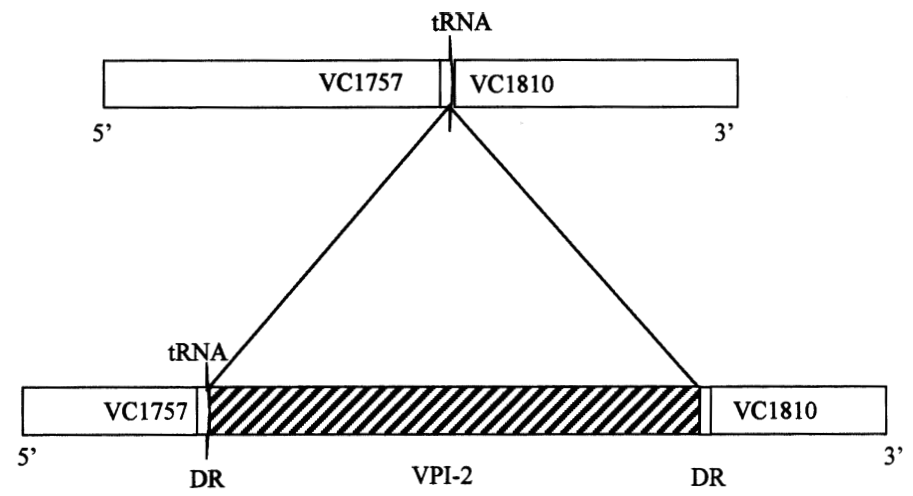

were used to verify the distribution of this region by Southern hybridization analysis (Fig. 1). Thus, hybridization analysis with these probes produced the expected 11.9 and $14.6 \mathrm{~kb}$ hybridization fragments, respectively, in all nanH-positive strains and the O139 serogroup strains, whereas no hybridization fragments were obtained for the nanH-negative $V$. cholerae strains examined (Fig. 2c and data not shown). The eighth primer pair, vc5B and vc6B, which amplifies gene VC1810, produced a $1.2 \mathrm{~kb}$ band with all toxigenic and nontoxigenic isolates examined, indicating the presence of this region in all isolates, and therefore marks the end of the 3 ' region unique to nan $H$-positive isolates (Fig. 3b).

Among the $13 \mathrm{~V}$. cholerae $\mathrm{O} 139$ serogroup isolates that contained a deletion within VPI-2, a primer pair ( $f k 3$ and $\mathrm{fk} 4$ ) was used to determine whether the region between the int gene (VC1758) and the IS911-like element (VC1789) was 'empty' in these isolates. Primer $\mathrm{fk} 3$ was designed $300 \mathrm{bp}$ from the end of int (VC1758) and primer fk 4 was designed within $100 \mathrm{bp}$ from the start of IS911 (VC1789) (Fig. 1). A 3.8 kb PCR product was amplified from all 13 O139 serogroup isolates, indicating the absence of additional DNA at this site. The $3.8 \mathrm{~kb}$ PCR product was sequenced and analysed using the BLAST program (Altschul et al., 1997) to reveal the presence of the VC1759 gene and a truncated VC1760 gene (Fig. 4). Sequencing showed that the VC1760 gene has a 665 bp deletion in the $3^{\prime}$ region of the gene and this partial VC1760 sequence is adjacent to the IS911-like sequence in the $13 \mathrm{O} 139$ isolates (data not shown).

Overall, it appears that $V$. cholerae toxigenic isolates contain a unique $57 \cdot 3 \mathrm{~kb}$ region, which we named VPI2 , that is absent from most non-toxigenic isolates. Only one O139 strain, MO2, which was isolated from Madras in 1992 contains the entire $57 \cdot 3 \mathrm{~kb}$. In $13 \mathrm{O} 139$ strains examined most of the $5^{\prime}$ region of VPI-2 is deleted with a $20.0 \mathrm{~kb}$ region remaining, which encompasses genes VC1758, VC1759, the partial sequence of VC1760 and VC1789 to VC1809 (Fig. 4). The VC1789 to VC1809 genes show homology to a number of bacteriophage genes (Table 4). The 13 O139 serogroup isolates that contained the truncated VPI-2 include two strains (MO10 and MO45) isolated from Madras in 1992, eight strains (AS207, AS209, AS210, AS212, AS213, AS231, AS259 and AS260) isolated from Calcutta in 1996, two strains (36054/98, 35636/97) isolated from Bangladesh in 1997 and 1998, and one strain (SG20) isolated from Calcutta. 


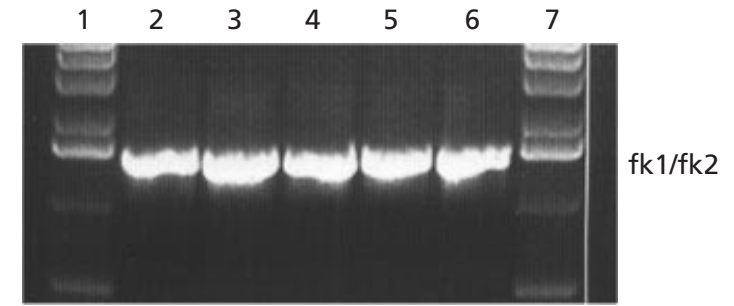

Fig. 7. $P C R$ analysis of VPI-2-negative strains to determine whether the region between the $5^{\prime}$ serine tRNA gene and the $3^{\prime}$ VC1810 gene is 'empty' or contains unique DNA. Lanes: 1, 7, $1 \mathrm{~kb}$ molecular mass marker; 2, 1528-79; 3, SG3; 4, SG6; 5, SG7; 6, SG10. A $1.6 \mathrm{~kb}$ band was obtained from all VPI-2-negative strains, using the primer pair $\mathrm{fk} 1$ and $\mathrm{fk} 2$, indicating that no significant additional DNA was inserted into the region.

\section{Characterization of the insertion site of VPI-2}

To determine the insertion site of VPI-2 in toxigenic $V$. cholerae isolates, the left junction of VPI-2 was investigated using primer lr1 designed from part of the chromosome-specific DNA of VC1757 and primer lr2 designed from specific VPI-2 island DNA (VC1758) (Fig. 1 and Table 2). As expected a $1.6 \mathrm{~kb}$ PCR fragment was obtained with all 45 VPI-2 island-positive strains and the 13 O139 serogroup isolates, whereas no PCR band was obtained with VPI-2-negative strains (Fig. 5a). The insertion site of the right junction of VPI-2 was studied using the primer pair $1808 \mathrm{~F}$, designed from specific VPI2 DNA (VC1808), and vc6A, designed from part of the chromosomal DNA of VC1810 (Fig. 1 and Table 2). These primers generated an expected $2.8 \mathrm{~kb}$ PCR band in all VPI-2-positive strains and the $13 \mathrm{O} 139$ serogroup isolates. VPI-2-negative V. cholerae strains gave no PCR band (Fig. 5b). Sequence analysis of the insertion site revealed the presence of a $7 \mathrm{bp}$ direct repeat at the $3^{\prime}$ end of the serine tRNA gene (Fig. 6). This $7 \mathrm{bp}$ repeat sequence could mark the potential chromosomal integration site of VPI-2 in the V. cholerae.

$V$. cholerae VPI-2-negative strains were further analysed to determine whether the region between the $5^{\prime}$ serine tRNA gene and the 3' VC1810 gene was 'empty' or contained unique DNA. A primer pair fk1 and fk2 was designed from chromosome-specific DNA of VC1757 and VC1810, which lie respectively in the left and right chromosomal junction fragment of VPI-2. VPI-2-negative strains produced a $1.6 \mathrm{~kb}$ product, which is slightly larger than the expected $1.0 \mathrm{~kb}$ product, but indicates that this region does not contain any significant additional DNA (Fig. 7). Analysis of VPI-2-positive $V$. cholerae strains did not yield a PCR product as expected, since these strains contain the entire VPI-2 or the truncated island which is beyond the capabilities of PCR amplification under the conditions employed.

\section{Sequence analysis of the VPI-2 pathogenicity island}

The first gene within VPI-2, int, lies immediately downstream of serine tRNA gene (Fig. 1). The int gene shows similarity (51\% amino acid identity) to the int gene described in the VPI encoding TCP (Karaolis et al., 1998) (Table 4). The int gene is preceded by a $247 \mathrm{bp}$ non-coding region carrying a $35 \mathrm{bp}$ sequence that is $88 \%$ identical to the region between the int and ssrA tRNA-like gene of the VPI (data not shown). However, the homology between VPI-2 and the VPI ends immediately $3^{\prime}$ of the int genes. This indicates that the mechanism of insertion of the VPI and VPI-2 may have common features, but the genes within each island are distinct.

VPI- 2 contains a total of 52 ORFs and is $57 \cdot 3 \mathrm{~kb}$ in length. The overall G $+\mathrm{C}$ content of VPI-2 $(42 \mathrm{~mol} \%)$ is lower than that of the entire $V$. cholerae genome $(47-49 \mathrm{~mol} \%)$. Of the 52 ORFs (VC1758-VC1809), 13 ORFs showed similarity to bacteriophage genes, 29 ORFs were homologous to genes of known function and 10 ORFs showed no significant matches in the database (Table 4). Among the 29 ORFs of known function, a number of gene clusters were observed. For example, downstream of the int gene (VC1758), a restriction modification system (VC1764-VC1769), containing a type 1 restriction modification gene ( $h s d R$ ) and its associated DNA methylase gene ( $h s d M$ ) was identified, which showed sequence similarity to a restriction modification system from Xylella fastidiosa (Simpson et al., 2000). Adjacent to this region is a cluster of 11 genes (VC1773-VC1783) that showed considerable homology (27-52\% amino acid identity) to an equivalent gene cluster in the Haemophilus influenzae genome, encoding enzymes involved in the utilization of amino sugars (nan-nag region) (Fleischmann et al., 1995). The gene order in H. influenzae (nanE-nanK-HI0143-nanA-nagB$n a g A)$ is somewhat different to that in $V$. cholerae (nanA-VC1777-VC1778-VC1779-VC1780-nanE-nanK$n a g C)$, but it suggests a remarkable grouping of ORFs of related function. The nan-nag gene cluster is located immediately upstream of nanH and may potentially be involved in the utilization of sialic acid released by the enzymic action of this neuraminidase.

An IS-like element (VC1789-VC1790), located downstream of nanH, showed significant identity 66 and $72 \%$ ) to the Shigella flexneri IS911 element (Prere et al., 1991). Adjacent to this IS911-like element within a region that encompasses 19 ORFs (VC1791-VC1809), lie $10 \mathrm{ORFs}$ that exhibit striking amino acid similarities (identities ranging from 21 to $50 \%$ ) to ORFs of bacteriophage origin (Table 4). These 10 ORFs include genes encoding phage regulatory and tail functions. For example, the amino acid sequence of the ORFs VC1791 and VC1792 share similarity (identity $35 \%, E$ value $4 \mathrm{e}-$ 48 ; identity $33 \%$, $E$ value, 1e- 05 ) with the gp 42 protein and gp41 protein of Mu phage (Table 4). Furthermore, the ORFs VC1793, VC1794, VC1795, VC1796 and VC1799 all exhibit sequence similarity to bacteriophage proteins and two of these (VC1793 and VC1799) show similarity to a transposase and integrase protein, respectively, suggesting that these genes may be involved in the mobilization and integration of this region (Table 4). Additionally, the ORF VC1803 exhibits 33\% similarity with a repressor protein from phage $\mathrm{CP}-933 \mathrm{O}$ and 
the amino acid sequence of ORF VC1809 has a $50 \%$ identity ( $E$ value $3 \mathrm{e}-11$ ) with the Vis protein of P4. The IS911-like element is the first ORF that is present following the deletion of VC1761-VC1788 in the nanHnegative O139 serogroup strains.

\section{DISCUSSION}

In this study, we have identified a $57 \cdot 3 \mathrm{~kb}$ VPI, which we named VPI-2, that exhibits all the characteristics of a pathogenicity island. Thus, VPI-2 is present in pathogenic $V$. cholerae isolates and is absent from nonpathogenic isolates. VPI-2 encodes a neuraminidase, a type I restriction modification system, a gene cluster involved in the utilization of amino sugars, an eha homologue and several conserved ORFs of unknown function. The significance of neuraminidase in cholera pathogenesis remains unclear. However, given our incomplete knowledge of $V$. cholerae pathogenesis it is possible that genes within VPI-2 may play a role in virulence. VPI-2 has a G $+\mathrm{C}$ content of $42 \mathrm{~mol} \%$ that is considerably lower than that of the entire $V$. cholerae genome (47-49 $\mathrm{mol} \%$ ) and encodes a bacteriophagelike integrase (int), as well as a number of potential mobility genes, such as a transposase-like gene and an IS911-like insertion sequence.

In V. cholerae, VPI-2 is located within the $3^{\prime}$ end of a serine tRNA gene. The tRNA loci serve as conserved genomic landmarks for the insertion of mobile genetic elements (bacteriophages and pathogenicity islands) in a range of bacterial pathogens. For example, among pathogenic E. coli isolates five pathogenicity islands, PAI-1 and LEE, PAI-2, PAI-4 and PAI-5 have insertion sites in selC, leuX, pheR and $p h e V$, respectively (Blum et al., 1994; Hacker et al., 1997; McDaniel \& Kaper, 1997). These same tRNA genes also serve as integration sites for different bacteriophages in E. coli K-12 and O157 strain EDL933 (Blattner et al., 1997; Perna et al., 2001). Furthermore, the serine tRNA locus in particular serves as the insertion site for the vap region from Dichelobacter nodosus (Cheetham et al., 1995), SPI-5 in Salmonella enterica serovar Typhimurium (Wood et al., 1998), an $84 \mathrm{~kb}$ pathogenicity island in E. coli O157 strain EDL933 (Perna et al., 2001) and bacteriophage T12 of Streptococcus pyogenes (McShan et al., 1997).

An additional characteristic of some pathogenicity islands is their instability and the VPI-2 region between VC1760 (helicase) and VC1789 (IS911-like element), which includes the restriction modification system and the nan-nag regions, is deleted from 13 of the $14 \mathrm{~V}$. cholerae $\mathrm{O} 139$ serogroup strains examined. Of the 13 O139 strains with the truncated VPI-2 most were isolated after 1992. Only one O139 strain MO2, which was isolated in 1992, contains the entire $57 \cdot 3 \mathrm{~kb}$ VPI-2. A recent study by Dziejman et al. (2002) analysing differences in gene content between endemic and pandemic cholera isolates identified the same deletion of the region spanning VC1761-VC1786 in O139 serogroup strain MO10, consistent with our findings. In 1992 CTproducing V. cholerae $\mathrm{O} 139$ serogroup isolates emerged as the first non-O1 serogroup isolates to cause epidemic cholera in the Indian subcontinent, replacing the seventh pandemic V. cholerae O1 El Tor biotype strains (Albert et al., 1993; Cholera Working Group, 1993; Ramamurthy et al., 1993). However, the El Tor biotype, which was the progenitor for the $\mathrm{O} 139$ epidemic clone, soon re-emerged as the dominant cause of cholera in these areas (Faruque et al., 1997). A possible explanation for the re-emergence of El Tor cholera could be the presence of VPI-2 in the El Tor biotype and the deletion of most of VPI-2 from O139 serogroup strains.

The presence of $n a n H$ on a pathogenicity island suggests that it was acquired by horizontal transfer. Interestingly, it has been suggested that nanH from a number of bacterial pathogens was acquired by horizontal gene transfer (Hoyer et al., 1992; Roggentin et al., 1993). On the $S$. enterica serovar Typhimurium LT2 genome the $n a n H$ gene is encoded within a prophage Fels- 1 and shows a $\mathrm{G}+\mathrm{C}$ content $(47 \mathrm{~mol} \%)$ that differs from the host genome $(50 \mathrm{~mol} \%)$ (McClelland et al., 2001; Figueroa-Bossi, 2001). Similarly, in Clostridium perfringens, the nanH gene is located near a phage attachment site on the chromosome and has a G + C content of $31.9 \mathrm{~mol} \%$ compared to the chromosomal DNA G + C content of 24-27 mol\% (Canard \& Cole, 1989). In M. viridifaciens it has been observed that a region flanking the nanH gene shows significant homology to a transposase (Sakurada et al., 1992).

In $V$. cholerae, it is hypothesized that the function of neuraminidase, encoded by $n a n H$, is to act synergistically with CT by increasing the binding and penetration of the toxin to host enterocytes (Galen et al., 1992). However, these authors demonstrated only a modest effect of nanH on CT function in vitro and no significant effect in vivo in the suckling mouse model. Therefore, the true extent of the role of $n a n H$ in virulence remains unclear. We speculate that VPI-2 is likely to be important in pathogenesis, either directly in cholera virulence or indirectly in the transfer and integration of the island. The VPI-2 region may contribute to the survival of the bacterium in different ecological niches. For example, the product of nanH, neuraminidase, acts on higher order gangliosides converting them to $\mathrm{GM}_{1}$ gangliosides, with the subsequent release of sialic acid. The nan-nag region encodes proteins involved in the utilization of both $\mathrm{N}$-acetylglucosamine and sialic acid. The ability to utilize the sialic acid by-product as an alternative nutrient source could convey a significant competitive advantage to pathogenic $V$. cholerae strains. VPI-2 also encodes a number of ORFs of unknown function and we are now in the process of examining these regions for a possible role in V. cholerae pathogenesis.

\section{ACKNOWLEDGEMENTS}

We thank Yvonne O'Shea, Anne-Marie Quirke and Keith Neligan for helpful discussion. This research was funded by Enterprise Ireland and Higher Education Authority grants to E.F.B. 


\section{REFERENCES}

Albert, M. J., Siddique, A. K., Islam, M. S., Faruque, A. S., Ansaruzzaman, M., Faruque, S. M. \& Sack, R. B. (1993). Large outbreak of clinical cholera due to Vibrio cholerae non-O1 in Bangladesh. Lancet 341, 704.

Altschul, S., Madden, T., Schaffer, A., Zhang, J., Zhang, Z., Miller, W. \& Lipman, D. (1997). Gapped BLAST and PSI-BLAST: a new generation of protein database search programs. Nucleic Acids Res 25, 3389-3402.

Barua, D. (1992). History of cholera. In Cholera, pp. 1-36. Edited by D. Barua \& W. B. Greenough 3rd. New York: Plenum.

Berche, P., Poyart, C., Abachin, E., Lelievre, H., Vandepitte, J., Dodin, A. \& Fournier, J. M. (1994). The novel epidemic strain O139 is closely related to the pandemic strain O1 of Vibrio cholerae. J Infect Dis 170, 701-704.

Bik, E. M., Bunschoten, A. E., Gouw, R. D. \& Mooi, F. R. (1995). Genesis of the novel epidemic Vibrio cholerae O139 strain: evidence for horizontal transfer of genes involved in polysaccharide synthesis. EMBO J 14, 209-216.

Bik, E., Gouw, R. \& Mooi, F. (1996). DNA fingerprinting of Vibrio cholerae strains with a novel insertion sequence element: a tool to identify epidemic strains. J Clin Microbiol 34, 1453-1461.

Blattner, F. R., Plunkett, G. I., Bloch, C. A. \& 14 other authors (1997). The complete genome sequence of Escherichia coli K12. Science 277, 1453-1474.

Blum, G., Ott, M., Lischewski, A., Ritter, A., Imrich, H., Tschape, H. \& Hacker, J. (1994). Excision of large DNA regions termed pathogenicity islands from tRNA-specific loci in the chromosome of an Escherichia coli wild-type pathogen. Infect Immun 62, 606-614.

Canard, B. \& Cole, S. T. (1989). Genome organization of the anaerobic pathogen Clostridium perfringens. Proc Natl Acad Sci US A 86, 6676-6680.

Cheetham, B., Tattersall, D., Bloomfield, G., Rood, J. \& Katz, M. (1995). Identification of a gene encoding a bacteriophage-related integrase in a vap region of the Dichelobacter nodosus genome. Gene 162, 53-58.

Cholera Working Group. (1993). Large epidemic of cholera-like disease in Bangladesh caused by Vibrio cholerae non-O139 Bengal. Lancet 342, 387-390.

Comstock, L. E., Maneval, D., Jr, Panigrahi, P., Joseph, A., Levine, M. M., Kaper, J. B., Morris, J. G., Jr \& Johnson, J. A. (1995). The capsule and $\mathrm{O}$ antigen in Vibrio cholerae O139 Bengal are associated with a genetic region not present in Vibrio cholerae O1. Infect Immun 63, 317-323.

Dziejman, M., Balon, E., Boyd, D., Fraser, C. M., Heidelberg, J. F. \& Mekalanos, J. J. (2002). Comparative genomic analysis of Vibrio cholerae: genes that correlate with cholera endemic and pandemic disease. Proc Natl Acad Sci US A 99, 1556-1561.

Faruque, S. M., Ahmed, K. M., Abdul Alim, A. R. M., Qadri, F., Siddique, A. K. \& Albert, M. J. (1997). Emergence of a new clone of toxigenic Vibrio cholerae O1 biotype El Tor displacing V. cholerae O139 Bengal in Bangladesh. J Clin Microbiol 35, 624-630.

Figueroa-Bossi, N., Uzzau, S., Maloriol, D. \& Bossi, L. (2001). Variable assortment of prophages provides a transferable repertoire of pathogenic determinants in Salmonella. Mol Microbiol 39, 260-271.

Fleischmann, R. D., Adams, M. D., White, O. \& 37 other authors (1995). Whole-genome random sequencing and assembly of Haemophilus influenzae Rd. Science 269, 496-512.
Galen, J. E., Ketley, J. M., Fasano, A., Richardson, S. H., Wasserman, S. S. \& Kaper, J. B. (1992). Role of Vibrio cholerae neuraminidase in the function of cholera toxin. Infect Immun $\mathbf{6 0}$, 406-415.

Hacker, J., Blum-Oehler, G., Muhldorfer, I. \& Tschape, H. (1997). Pathogenicity islands of virulent bacteria: structure, function and impact on microbial evolution. Mol Microbiol 23, 1089-1097.

Heidelberg, J. F., Eisen, J. A., Nelson, W. C. \& 23 other authors (2000). DNA sequence of both chromosomes of the cholera pathogen Vibrio cholerae. Nature 406, 477-483.

Hoyer, L. L., Hamilton, A. C., Steenbergen, S. M. \& Vimr, E. R. (1992). Cloning, sequencing and distribution of the Salmonella typhimurium LT2 sialidase gene, nanH, provides evidence for interspecies gene transfer. Mol Microbiol 6, 873-884.

Kaper, J. B., Morris, J. G., Jr \& Levine, M. M. (1995). Cholera. Clin Microbiol Rev 8, 48-86.

Karaolis, D. K., Johnson, J. A., Bailey, C. C., Boedeker, E. C., Kaper, J. B. \& Reeves, P. R. (1998). A Vibrio cholerae pathogenicity island associated with epidemic and pandemic strains. Proc Natl Acad Sci US A 95, 3134-3139.

Karaolis, D. K., Somara, S., Maneval, D. R., Jr, Johnson, J. A. \& Kaper, J. B. (1999). A bacteriophage encoding a pathogenicity island, a type-IV pilus and a phage receptor in cholera bacteria. Nature 399, 375-379.

Kovach, M. E., Shaffer, M. D. \& Peterson, K. M. (1996). A putative integrase gene defines the distal end of a large cluster of ToxRregulated colonization genes in Vibrio cholerae. Microbiology $142,2165-2174$.

McClelland, M., Sanderson, K., Spieth, J. \& 23 other authors (2001). Complete genome sequence of Salmonella enterica serovar Typhimurium LT2. Nature 413, 852-856.

McDaniel, T. \& Kaper, J. (1997). A cloned pathogenicity island from enteropathogenic Escherichia coli confers the attaching and effacing phenotype on E. coli K-12. Mol Microbiol 23, 399-407.

McShan, W., Tang, Y. \& Ferretti, J. (1997). Bacteriophage T12 of Streptococcus pyogenes integrates into the gene encoding a serine tRNA. Mol Microbiol 23, 719-728.

O'Shea, Y. A. \& Boyd, E. F. (2002). Mobilization of the Vibrio pathogenicity island between Vibrio cholerae isolates mediated via CP-T1 generalized transduction. FEMS Microbiol Lett (in press).

Perna, N. T., Plunkett, G., III, Burland, V. \& 25 other authors (2001). Genome sequence of enterohemorrhagic Escherichia coli O157: H7. Nature 409, 529-533.

Prere, M., Chandler, M. \& Fayet, O. (1991). Transposition in Shigella dysenteriae: isolation and analysis of IS911, a new member of the IS3 group of insertion sequences. Res Microbiol 142, 489-498.

Ramamurthy, T., Garg, S., Sharma, R. \& others (1993). Emergence of a novel strain of Vibrio cholerae with epidemic potential in southern and eastern India. Lancet 341, 703-704.

Roggentin, P., Schauer, R., Hoyer, L. L. \& Vimr, E. R. (1993). The sialidase superfamily and its spread by horizontal gene transfer. Mol Microbiol 9, 915-921.

Sakurada, K., Ohta, T. \& Hasegawa, M. (1992). Cloning, expression and characterization of the Micromonspora viridifaciens neuraminidase in Streptomyces lividans. J Bacteriol 174, 6896-6903.

Sears, C. L. \& Kaper, J. L. (1996). Enteric bacterial toxins: mechanism of action and linkage to intestinal secretion. Microbiol Rev 60, 167-215. 
Simpson, A., Reinach, F. C., Arruda, P. \& 113 other authors (2000). The genome sequence of the plant pathogen Xylella fastidiosa. The Xylella fastidiosa Consortium of the Organization for Nucleotide Sequencing and Analysis. Nature 406, 151-157.

Stroeher, U. H., Parasivam, G., Dredge, B. K. \& Manning, P. A. (1997). Novel Vibrio cholerae O139 genes involved in lipopolysaccharide biosynthesis. J Bacteriol 179, 2740-2747.

Taylor, R. K., Miller, V. L., Furlong, D. B. \& Mekalanos, J. J. (1987). Use of $p h o A$ gene fusions to identify a pilus colonization factor co-ordinately regulated with cholera toxin. Proc Natl Acad Sci U S A 84, 2833-2837.
Waldor, M. K. \& Mekalanos, J. J. (1994). Vibrio cholerae O139 specific gene sequences. Lancet 343, 1366.

Waldor, M. K. \& Mekalanos, J. J. (1996). Lysogenic conversion by a filamentous phage encoding cholera toxin. Science 272, 19101914.

Wood, M., Jones, M., Watson, P., Hedges, S. \& Wallis, T. G. E. (1998). Identification of a pathogenicity island required for Salmonella enteropathogenicity. Mol Microbiol 29, 883-891.

Received 22 April 2002; revised 2 July 2002; accepted 30 July 2002. 